amount excreted and a constant level is reached after the second day with a total excretion of bile salts ranging between 50 and $80 \mathrm{mg} /$ day. These amounts have to be com. pared with the daily synthesis of bile acids in an intact animal. From the turnover time of labelled bile acids ${ }^{6}$ and the determinations of the amount of bile acids in the enterohepatic circulation by isotope dilution ${ }^{5}$ a daily synthesis of $2-3 \mathrm{mg}$ of bile acids in a $200 \mathrm{~g}$ rat has been calculated. In a bile fistula rat there is thus a $20-30$ fold increase of the normal bile acid production. This synthesis of bile acids in bile fistula rats is thus the result of a broken enterohepatic circulation. Further studies are in progress to elucidate factors regulating this process and its relation to the metabolism of cholesterol.

1. Bergström, S. and Norman, A. Proc. Soc. Exptl. Biol. Med. 83 (1953) 71.

2. Friedman, M., Byers, S. O. and Michaelis, F. Am. J. Physiol. 164 (1951) 786.

3. Thompson, J. C. and Vars, H. M. Proc. Soc. Exptl. Biol. Med. 83 (1953) 246.

4. Sjövall, J. Acta Chem. Scand. 9 (1955) 1034.

5. Bergström, S. and Eriksson, S. To be published.

6. Lindstedt, S. and Norman, A. Acta Chem. Scand. 9 (1955) 1042.

\section{Urea Solution as a Solvent for the Viscosimetric Determination of Lichenase Activity Eskil Hultin}

\section{Institutet för organisk kemi och biokemi,} Stockholm, Sweden

Viscosimetric methods are generally more sensitive than other methods for the determination of the activity of enzymes which are capable of breaking down polymer-homologous substances. It follows as a matter of course that a viscosimetric determination of enzymic activity can only be carried out with such substrates as are completely soluble and give solutions with a high viscosity.

Lichenin is a polysaccharide which is easily soluble only in warm alkaline water solution, and much of it is precipitated if the temperature and the $\mathrm{pH}$ are lowered to such values as are suitable for the investigation of the activity of lichenase. A new method for obtaining solutions of lichenin is suggested here.

It has turned out that lichenin is soluble in water solutions of urea.
The viscosimetric determination of lichenase can be carried out as follows. Lichenin is dissolved in a warm urea solution, containing 0.3 to $0.5 \mathrm{~g}$ urea for each gram of water. A lichenin concentration of a few per cent may have a viscosity of about 3 or 4 times that of the urea solution, which is convenient.

One $\mathrm{ml}$ of an enzyme solution and $1 \mathrm{ml}$ of a buffer solution are transferred to an Erlenmeyer flask. Two $\mathrm{ml}$ of the lichenin solution are added, and the contents are thoroughly mixed. Two $\mathrm{ml}$ of the reaction mixtures are transferred to a dry Ostwald viscosimeter, and a timer is started. The flow time is measured several times.

The inverse value of the specific viscosity is computed for each flow time by dividing the flow time for the solvent by the flow time of the reaction mixture diminished by the flow time of the solvent.

The inverse values of the specific viscosity are plotted in a diagram versus the times, for which they are valid, and a straight line is fitted to the points. The inclination of the line, multiplied by the square of the concentration of lichenin in the reaction mixture, is a measure of the enzyme activity.

By this viscosimetrical method it was shown that sperm of Paracentrotus lividus contain lichenase in small quantities.

The method suggested here - dissolving. lichenin in a urea solution - has the advantage, that the true solution of even a high molecular fraction of the naturally occurring substrate, and not its hydroxy ethyl or carboxy methyl ether - as is the case with cellulose and chitin - can be used for the assay of enzymes capable of splitting $\beta-1,4$ glucoside linkages.

\section{Sialic Acid and Neuraminic Acid Gunnar Blix}

\author{
Institute of Medical Chemistry, University of \\ Uppsala, Sweden
}

The structure of sialic acid and of neuraminic acid is discussed principally on the basis of group analyses and periodate oxidations and with particular regard to the ideas recently put forward by Gottschalk ${ }^{1}$. The structures proposed by this author are in the main in good agreement with our findings.

1. Gottschalk, A. Nature 176 (1955) 881. 